\title{
Efeitos auditivos ocasionados pelo uso excessivo do fone de ouvido
}

\author{
Times hearing effects caused by overuse of headphones \\ Efectos auditivos causados por el uso excessivo de auriculares
}

Recebido: 24/11/2021 | Revisado: 28/11/2021 | Aceito: 03/12/2021 | Publicado: 13/12/2021

Nara Lorena Furtado Pacheco

ORCID: https://orcid.org/0000-0002-5226-6244

Faculdade de Ensino Superior do Piauí, Brasil

E-mail: naralorenafurtadopacheco@gmail.com

Ruth Raquel Soares de Farias

ORCID: https://orcid.org/0000-0002-0988-0900

Faculdade de Ensino Superior do Piauí, Brasil E-mail: ruthraquelsf@gmail.com

Tamires Moura de Saboia

ORCID: https://orcid.org/0000-0003-3060-7834

Faculdade de Ensino Superior do Piaú, Brasil

E-mail: tamiressaboia@grupomagister.com.br

\begin{abstract}
Resumo
O hábito de usar fones de ouvido vem crescendo gradativamente na vida das pessoas, principalmente entre o público jovem. Tendo em vista a carência de informações sobre os malefícios ocasionados pelo uso incorreto do fone de ouvido, este artigo tem como objetivo de relatar sobre as possíveis consequências para a saúde auditiva que os usuários estão expostos. Trata-se de uma revisão integrativa de literatura onde foram selecionados vários artigos utilizando as plataformas do Google Scholar, LILACS, SCIELO. Uma estimativa da Organização Mundial de Saúde mostra que cerca de 5\% das perdas de audição no Brasil, aproximadamente 1,5 milhão de pessoas, estão relacionadas à utilização indevida do fone de ouvido. $\mathrm{O}$ uso irregular do fone de ouvido provoca uma série de riscos para a saúde auditiva das pessoas, podendo causar perda auditiva e zumbidos no ouvido.
\end{abstract}

Palavras-chave: Saúde auditiva; Fone de ouvido; Hábitos auditivos; Perda auditiva.

\begin{abstract}
The habit of using headphones has been growing gradually in people's lives, especially among the young audience. In view of the lack of information about the harm caused by the incorrect use of headphones, this article aims to report on the possible consequences for hearing health that users are exposed to. This is an integrative literature review where several articles were selected using the platforms of Google Scholar, LILACS, SCIELO. An estimate by the World Health Organization shows that about $5 \%$ of hearing losses in Brazil, approximately 1.5 million people, are related to the misuse of headphones. Irregular use of headphones causes a series of risks to people's hearing health, which can cause hearing loss and rinring in the ear.
\end{abstract}

Keywords: Hearing health; Earphone; Hearing habits; Hearing loss.

\section{Resumen}

El hábito de usar auriculares ha ido creciendo paulatinamente en la vida de las personas, especialmente entre el público joven. Ante la falta de información sobre el daño causado por el uso incorrecto de los auriculares, este artículo tiene como objetivo informar sobre las posibles consecuencias para la salud auditiva a las que están expuestos los usuarios. Se trata de una revisión de literatura integradora donde se seleccionaron varios artículos utilizando las plataformas de Google Scholar, LILACS, SCIELO. Una estimación de la Organización Mundial de la Salud muestra que alrededor del 5\% de las pérdidas auditivas en Brasil, aproximadamente 1,5 millones de personas, están relacionadas con el mal uso de los auriculares. El uso irregular de auriculares provoca una serie de riesgos para la salud auditiva de las personas, que pueden provocar pérdida auditiva y zumbidos en el oído.

Palabras clave: Salud auditiva; Audíofono; Hábitos auditivos; Perda de la audición.

\section{Introdução}

A Organização Mundial da Saúde (OMS) aponta que aproximadamente mais de um bilhão de adolescentes e do público de jovens adultos correm o risco de perda auditiva devido à exposição a níveis excessivos de som alto em locais de entretenimento e devido também ao uso inseguro de dispositivos pessoais de áudio. Atualmente, a exposição a ruídos tem 
aumentado gradativamente, se tornando um dos maiores agentes nocivos à saúde nos ambientes urbanos e sociais (Silva, et al., 2012).

Todos os dias, é comum vermos pessoas dentro do transporte público, em reunião de trabalho ou fazendo atividades físicas, portando fones de ouvido. O uso deste recurso tem se tornado cada vez mais frequente independentemente do local, em atividades rotineiras ou de lazer. A modernização do fone de ouvido também é um fator que contribui para essa popularidade, que atualmente está disponível em diversos modelos, cores e funções, assim podendo suprir as necessidades e preferências particulares de cada um.

A audição é um dos cinco sentidos do ser humano. É a capacidade de percepcionar o som, por meio deste sentido ouvimos e identificamos todos os sons do ambiente. A audição tem uma função bastante complexa e primordial na comunicação humana e preservação da espécie, lesões nas estruturas sensoriais da audição provocam prejuízos na detecção, localização e discriminação dos sons (Luz \& Borja, 2012).

Com o crescimento da urbanização e o avanço tecnológico, durante o dia estamos sempre expostos aos mais diferentes ruídos. Além disso, o acesso a aparelhos celulares, computadores e jogos ocorre cada vez mais cedo, e normalmente para utilizar são conectados em equipamentos de amplificação sonora, sendo o mais popular entre eles "o fone de ouvido", que normalmente é usado por muitas horas durante o dia. O que muitos não tem conhecimento, apesar de esporádicos, é que essas exposições ao som intenso podem trazer malefícios ao ser humano, podendo alterar seu bem-estar físico e mental. (Silva, et al., 2012).

De acordo com Borja, et al., (2002), o fone de ouvido desenvolve uma intensidade sonora que varia de $60 \mathrm{a} 120 \mathrm{db}$ tornando-se prejudicial para a saúde auditiva. Quando essa exposição ao ruído é de forma brusca e muito intensa, pode ocorrer o trauma acústico, lesando de forma temporária ou definitiva diversas estruturas do ouvido. Outro tipo de alteração auditiva que é provocado pela exposição ao ruído intenso é a mudança transitória de limiar, que se caracteriza por uma diminuição da acuidade auditiva que pode retornar ao normal, após um período de afastamento do ruído.

O estudo das estruturas, que formam o sistema auditivo é de fundamental importância para o diagnóstico clínico considerado preciso. Por isso a fonoaudiologia, especialmente na área de audiologia é importante para contribuir no diagnostico audiológico e quando necessário, realizar uma intervenção terapêutica, quando houver disfunções auditivas. Disfunções que tem como alternativa ter sido causada pela exposição á ruído. A partir desse pressuposto, surge o questionamento: Quais os malefícios a curto e a longo prazo que o uso inadequado do fone de ouvido pode trazer para a saúde auditiva?

O objetivo deste trabalho de revisão de literatura é discorrer sobre o tema "efeitos ocasionados pelo uso excessivo do fone de ouvido" uma vez que é pouco conhecido e explorado pela população brasileira. Privilegiando demonstrar como o uso incorreto do fone de ouvido pode trazer prejuízos para a saúde auditiva e a importância da fonoaudiologia dentro desta área audiológica.

A motivação deste estudo é porque de uma maneira geral, as pessoas não se preocupam com questões atinentes com a prevenção dos mais diversos problemas auditivos, problemas estes que quando acontecem além de abalar fortemente o sentido da audição, traz uma série de malefícios que afetam negativamente tanto a saúde física, como também a saúde mental dos seres humanos.

\section{Referencial Teórico}

\subsection{Audição}

O portal para recepção do som tem mil formas, e nós o adornamos de mil maneiras, mas a sua verdadeira graciosidade está oculta no fundo do crânio. A audição é o único órgão dos sentidos que tem duas funções totalmente diferentes, ele capta os 
sons e nos matem equilibrados. Graças a audição, nos mantemos contato constante com que acontece ao redor. Os ouvidos estão sintonizados na frequência dos sons da fala, o meio de comunicação exclusivamente humano.

Os ouvidos são capazes de distinguir milhões de tons diferentes, nos fazendo capazes de reconhecer amigos e conhecidos pelas sutis diferenças entres suas vozes, conseguimos entender o que dizem em meio a um turbilhão de distrações e podemos até identificar sua localização só pelo som. Nosso senso de direção depende principalmente da existência dos ouvidos, uma voz do lado esquerdo alcança primeiro o ouvido esquerdo, indicando a ela a posição exata de onde veio, mesmo em um intervalo de poucos segundos.

Dentro do ouvido, apenas algumas partes são responsáveis pela audição, o tímpano, conjunto de ossos (ossículos) e a cóclea. o tímpano que separa o mundo externo do mecanismo interior do ouvido. Assim, vibra com cada som que ouvimos um movimento simples, mas que é responsável por introduzir todo o processo da audição. Depois do tímpano o som segue um caminho complexo dentro do ouvido, antes de ser finalmente analisado pela estrutura espiralada do ouvido, que é a cóclea. É uma jornada dentro de uma das menores estruturas do corpo humano.

Do tímpano o som viaja pelo ouvido médio, que é uma cavidade cheia de ar que tem apenas 8mm de extensão. as vibrações do tímpano são transmitidas para três ossos minúsculos, o martelo em primeiro, a bigorna em segundo, e em terceiro o menor osso do corpo humano.

Adequadamente chamado de estribo, esses ossos agem como minúsculas alavancas, intencionando a pressão das ondas sonoras mais de 20 vezes, mas este mecanismo também serve de defesas para as delicadas estruturas mais adiante. Se o tímpano for atingido por um som muito alto, os dois menores músculos do corpo humano, o tensor do tímpano e o estapedio se contraem e controlam as impetuosas vibrações dos ciclos.

A jornada das ondas sonoras pelo ouvido médio termina com a vibração no ossículo estribo, que faz pressão sobre uma fina membrana chamada janela oval. Mais à frente estão as cavidades cheia de fluido do ouvido interno, a cóclea. É a estrutura espiralada que está enterrada na parte mais espessa do crânio, a cóclea é do tamanho de uma ervilha e contém um mecanismo de complexidade impressionante. Percorrendo todo o caminho espiral da cóclea está o microfone, do corpo, o órgão de corti. Esse órgão transforma as vibrações sonoras em sinais elétricos que percorrem o sistema nervoso, que é a rede de comunicação que liga todas as partes do corpo.

Quando as vibrações chegam até as células ciliadas, fazem com que seus cílios oscilem saindo de sua posição de repouso. A oscilação dos cílios causa uma mudança na carga elétrica endocelular, transformando o som em sinais elétricos codificados para volume e tons. É um disparo de impulso elétrico para as fibras nervosas que é conduzido para o nervo acústico e para o cérebro. Quando são ativadas pela música as extremidades ciliadas de cada célula, dançam mais depressa do que qualquer outra célula seria capaz, estes minúsculos pelos são tudo o que existe entre nós e o silencio (Guyton \& Hall, 2017).

Com base nos parágrafos anteriores onde foi argumentado sobre as questões relacionadas com a audição de uma forma geral, desde a orelha externa até a orelha interna fica fácil à compreensão sobre o seu funcionamento. Conseguimos demonstrar como o ouvido é um triunfo da biônica, é uma união componente de acústica, mecânica, hidráulica, eletrônica e miniaturização. Nas próximas sessões será abordado como o uso incorreto do fone de ouvido afeta e lesa as estruturas da audição.

\subsection{Perda auditiva}

O Brasil atualmente possui aproximadamente 10 milhões de pessoas com perda auditiva, e apenas $9 \%$ delas nasceram com essa condição. A grande maioria vai perdendo a audição ao longo da vida, principalmente nas últimas décadas. Apesar da 
perda auditiva ser relativamente comum, as pessoas só têm conhecimento das causas e dos tratamentos possíveis quando acontece com algum amigo ou pessoa próxima.

A perda auditiva é a dificuldade na recepção acústica, podendo acarretar o comprometimento em todos os níveis linguísticos (Mendes \& Barzaghi, 2011). De acordo com Silman e Silverman (1997), as perdas auditivas podem ser classificadas em três tipos: condutivas, neurossensoriais e mistas.

Para Santos, et al., (2011) a deficiência auditiva do tipo condutiva pode ser especificada quando ocorre a deficiência de transmissão, onde o problema está localizado no ouvido externo ou médio, nestes casos, o prognóstico comumente são bons. Quando se trata de uma deficiência do tipo mista, o problema está localizado no ouvido médio e interno, e deficiência do tipo neurossensorial, o problema se origina no ouvido interno e no nervo auditivo. Em casos de perdas do tipo neurossensorial em geral, são irreversíveis.

Para a classificação do grau das perdas auditivas, normalmente é usado o parâmetro adaptado da publicação da British Society of Audiology, cuja perda leve onde os limiares estão entre 25 e $40 \mathrm{~dB}$ NA, na moderada 41 a $70 \mathrm{~dB}$ NA, severa 71 a 95 dB NA e profunda $>95$ dB NA.

A perda auditiva tem inúmeros fatores que contribuem para que se origine, os mais comuns são: hereditariedade, genética, presbiacusia (que é o processo natural de envelhecimento), lesão traumática, medicação ototoxica e a exposição ao ruído intenso ou constante, que também é chamada de PAIR.

\subsection{Perda auditiva induzida por ruída}

O agente físico nocivo mais comum em nosso ambiente é o ruído. As consequências da exposição ao ruído intenso ou prolongado pode causar perda irreversível da audição, doença conhecida como perda auditiva induzida pelo ruído (PAIR) (Silva, et al., 2012).

Segundo Teles e Medeiros, (2007, p. 233) "O ruído é considerado todo sinal acústico aperiódico, originado da superposição de vários movimentos de vibração com diferentes frequências, as quais não apresentam relação entre si, já subjetivamente, considera-se como ruído toda sensação de desagrado, desconforto e/ou de intolerância decorrente de uma exposição sonora".

Desse modo, o aparelho auditivo humano é bastante frágil à ação do ruído, que pode atingir níveis muito elevados, capazes de prejudicar a audição e a saúde em geral. As lesões auditivas produzidas pelo ruído podem ser agudas ou crônicas, sendo que a mais comum é a crônica, que tem instalação lenta, muitas vezes a pessoa só se dá conta quando os zumbidos se tornam incômodos a ponto de chamar atenção para o problema (Barros, et al., 2007).

Esses zumbidos geram dificuldade de entendimento, principalmente nas faixas dos sons agudos e dificultam a compreensão da fala, especialmente em ambientes com elevado ruído de fundo. As consequências não se limitam somente a danos auditivos, mas compromete de forma relevante todo o organismo.

Conforme a Portaria do INSS com respeito à perda auditiva por ruído ocupacional, a perda auditiva induzida por ruído (PAIR) é uma doença crônica e irreversível, resultante da agressão às células ciliadas do órgão de corti, que decorre da exposição sistemática e prolongada a ruído, cujos níveis de pressão sonora (NPS) são elevados. Além disso, pode ser conceituada como uma redução gradual da acuidade auditiva decorrente da exposição continua níveis elevados de ruído. Ainda, possui característica audiométrica de ser sempre neurossensorial se não houver outra causa associada, geralmente bilateral e similar, não ultrapassando 40db (NA) nas freqs. Graves e os 75db (NA) nas frequências agudas.

Mediante Bouccara, et al., (2006), as deficiências auditivas relacionadas ao ruído são prontamente latentes, elas são descobertas durante a triagem sistemática ou em um estágio relativamente avançado, quando a deficiência funcional é óbvia, os 
fatores que irão influenciar a gravidade da deficiência auditiva são as intensidades sonoras a que a pessoa é exposta, a idade e a duração da exposição.

O diagnóstico da PAIR deve ser realizado através da avaliação clínica ou ocupacional, onde é coletado o detalhamento da exposição a fim de buscar relação entre a exposição e os sinais e sintomas, realização de exame otorrinolaringológico com ênfase na otoscopia e exame audiométrico tonal limiar. As frequências avaliadas são as tradicionais acrescidas de 3 e $6 \mathrm{kHz}$. A pessoa avaliada deve realizar, antes do exame, um repouso acústico de pelo menos 14 horas, com o intuito de ser evitado a detecção de uma perda auditiva temporária

Diante disso, observa-se que o ruído está presente diariamente na vida de milhões de pessoas, seja em casa, ou no trabalho. Além dessas exposições inevitáveis, muitos ainda fazem o uso do fone de ouvido por período prolongado ou em alta intensidade, colocando a audição em risco maior de ter lesões ocasionadas por ruído. Com base nisso, no próximo tópico serão abordados os hábitos auditivos que causam problemas na audição.

\subsection{Hábitos auditivos}

As mudanças sociais estão aumentando cada vez mais a exposição ao ruido, inúmeras casas de shows, bares e boates são abertas anualmente, e são nessas atividades de lazer onde é visto geralmente a intensidade do som estar igual ou superior a $100 \mathrm{db}$, trazendo riscos para integridade auditiva de cada um ali presente. Além disso, existe um fator ainda mais preocupante para a saúde auditiva, o uso dos "fone de ouvido", que são equipamento portáteis que podem chegar até a 120 decibéis no volume máximo.

Desde a criação do fone de ouvido, houve diversas mudanças e modernizações de suas funções e aparência, nos últimos anos foi criado o modelo de fone de ouvido sem fio, que logo em seguida também passou por diversas modificações para ficar o mais prático e portátil possível. Recentemente foi lançado o fone de ouvido do tipo "intra-articulares ou in-ear", cuja parte da estrutura é inserida dentro do canal auditivo externo impedindo que os sons externos atrapalhem o som no ouvido, sendo este atualmente o favorito de muitos, por conta de sua portabilidade, formato e conforto (Valeri, 2021).

Para evitar que ocorram danos à audição, o volume do som não pode, de forma alguma, ultrapassar $60 \%$ da capacidade máxima do aparelho, sendo que a maioria dos aparelhos já possui uma configuração de segurança. Em alguns celulares e computadores a barra indicativa do som é dividida por meio de quadradinhos com cada um representando $10 \%$ da capacidade do aparelho. Ainda pode ser compreendido como outra orientação o fato de que o volume não seja tão alto ao ponto do usuário não escutar os sons à sua volta, sendo recomendado realizar intervalos entre um uso prolongado e outro (Gonçalves \& Dias, 2014).

O uso do fone de ouvido não é em si um problema, mas sim o uso inadequado, o exagero no tempo de uso e a intensidade do volume. De acordo com Araújo (2002), o ruido em excesso tem a capacidade de lesar considerável extensão das vias auditivas, desde a membrana timpânica até regiões do sistema nervoso central. apesar que as lesões mais relevantes ocorrem no órgão de corti, na área espira basal da cóclea, que é responsável pela audição de sons de 3 a 6kHz.

Em um estudo realizado por Silva (2017), mostrou que 80 sujeitos com média de idade de 11,2 anos, usuários e não usuários de fones de ouvido foram avaliados com exame audiológicos de audiometria e timpanometria, 63\% dos sujeitos eram usuários de fones de ouvido, e os 36,2\% restantes eram não usuários. No resultado da audiometria tonal observou "trauma acústico" em 49\% das orelhas dos usuários de fones de ouvido, e em 15,5\% dos não usuários. Após comparar os resultados da pesquisa, foi confirmado " dano auditivo" em mais do dobro das orelhas dos usuários de fones de ouvido em comparação com os não usuários.

Além da perda auditiva, alguns outros sintomas são indicativos de que uso inadequado do fone de ouvido já está trazendo consequências irreversíveis para a audição como o zumbido, dificuldade de discriminação dos sons, plenitude 
auricular. Os sintomas extras auditivos mais frequentes que são: mudanças comportamentais, alteração no sono, alterações cardiovasculares, vestibulares, digestivas e neurológicas (Brasil, 2006).

Segundo Borja, et al., (2002, p. 86) é esperado para o futuro, uma geração de "surdos", resultante do modernismo, e imprudência dos usuários. A fim de reduzir essas expectativas, medidas e intervenções já começaram a ser criadas. Uma delas consiste na emissão de sinais sonoros como apitos e alertas, com o intuito de alertar o usuário que o volume já ultrapassou o limite saudável, além disso, profissionais da saúde frequentemente fazem movimentos como, palestras, campanhas, triagens com o propósito de informar sobre a importância do cuidado com a audição.

\subsection{Fonoaudiologia e perda auditiva}

De acordo com a Lei n. ${ }^{\circ}$ 6.965/1981 o Fonoaudiólogo é o profissional, com graduação em fonoaudiologia que atua em pesquisa, prevenção, avaliação e terapia fonoaudiológicas na área da comunicação oral e escrita, voz e audição, bem como em aperfeiçoamento dos padrões da fala e da voz.

A especialidade em audiologia foi uma das primeiras áreas a ser reconhecida pelo Conselho Federal de Fonoaudiologia (CFFa), nesta área o fonoaudiólogo atua na recuperação de diversos distúrbios auditivos, proporcionando desde terapias até à adaptação de aparelhos de Amplificação Sonora Individual (AASI), os conhecidos aparelhos auditivos, para aqueles que perderam parcialmente a audição.

Dessa forma, Miller (1974) revela que o fonoaudiólogo é o profissional responsável pela função social da audição e aborda a utilidade prática da capacidade auditiva, visando aumentar a habilidade do deficiente auditivo em lidar com as situações da vida diária. Atualmente, o fonoaudiólogo ou o médico, são os profissionais responsáveis para efetuar o processo de confirmação da alteração auditiva, a "avaliação audiológica", onde é realizado os exames de audiometria tonal por via aérea e via óssea, logoaudiometria e imitanciometria.

Logo, após a confirmação da perda auditiva, dependendo do tipo de perda, pode haver tratamento ou não. Quando as tentativas terapêuticas não apresentam solução, como no caso das perdas auditivas provocadas pelo uso excessivo do fone de ouvido, por se tratar de uma alteração auditiva neurossensorial, o indivíduo realiza o acompanhado da progressão da perda, e é encaminhado para a prótese auditiva, que segundo Broca e Scharlach (2014, p. 1808) tem a função de amplificar os sons a um determinado grau e modo que permitirá a utilizar a adição remanescente de modo efetivo.

Em sua tese, Kopstein (1999) cita que o fonoaudiólogo especialista em prótese auditiva, faz a seleção do melhor aparelho para cada indivíduo portador de deficiência auditiva, os procedimentos podem variar desde técnicas matematicamente fundamentais até métodos mais informais baseados tanto na experiência do fonoaudiólogo, quanto na impressão subjetiva do próprio usuário sobre o aparelho de amplificação.

Ainda sobre as funções do profissional de fonoaudiologia na perda auditiva, existe também o seu papel na prevenção, que se presenciam cada vez mais, a fim de evitar alterações auditivas. É comum a realização de eventos e campanhas onde ocorre a orientação da importância da audição, e informações sobre o que muitos não têm conhecimento dos hábitos e exposições do dia a dia que podem causar lesões na audição. Triagens auditivas também são realizadas nesses eventos com o intuito de encaminhar suspeitos de alteração para realização dos procedimentos para diagnostico.

Desta maneira, é oportuno analisar as evidências científicas sobre os efeitos auditivos ocasionados pelo fone de ouvido, fato que oferecem dados tanto para o atendimento clínico quanto para pesquisas futuras. Assim, o objetivo deste estudo foi sintetizar as evidências existentes na literatura a respeito do uso excessivo do fone de ouvido.

Diante disso, observa-se que ainda existe carência de conhecimento nesta área, uma vez que foram encontrados para a fundamentação deste trabalho pouco assunto relacionado. Logo, isso demonstra a grande necessidade de uma intervenção fonoaudiológica. 


\section{Metodologia}

A metodologia da presente pesquisa, consiste em uma revisão de literatura do tipo integrativa. Esse tipo de revisão é caracterizado por Ercole, et al., (2014, p. 9), como: "um método que tem como finalidade sintetizar resultados obtidos em pesquisas sobre um tema ou questão, de maneira sistemática, ordenada e abrangente". Dessa maneira, a revisão integrativa permite a busca de informações mais amplas sobre a temática em estudo.

Quanto aos procedimentos da pesquisa, foi realizada uma pesquisa bibliográfica em livros e pela internet, por meio de bases de dados e plataformas digitais: LILACS (Literatura Latina Americana), SCIELO (Scientífic Eletrônic Library Online), e Google Acadêmico, em busca de estudos que forneçam temas relacionados a temática da pesquisa, contribuindo assim para uma melhor execução do estudo. Como critério de inclusão dos artigos científicos, foram selecionados os textos completos, no idioma português, com anos de referências de 2010 a 2021 e que estavam dentro dos descritores escolhidos.

Ao pesquisar sobre a temática nas bases de dados e analisar os títulos e resumos, foram encontrados 213 artigos completos. Dentre eles, 193 não respondiam à pergunta norteadora e 16 não se encaixavam nos critérios de recorte temporário (2010 - 2021). Sendo assim, foram utilizados 4 artigos para a revisão integrativa desta pesquisa.

Baseado nisso, os conceitos discutidos a seguir serão utilizados com intuito de auxiliar a análise deste estudo. Tendo em vista que, o fundamento teórico foi estruturado para oferecer uma melhor compreensão sobre os efeitos auditivos ocasionados pelo uso excessivo do fone de ouvido.

\section{Resultados e Discussão}

Após analisar as diversas teorias, presentes em artigos científicos, monografias, dissertações, livros e consultas em sites eletrônicos, analisando principalmente revistas científicas, referente aos efeitos auditivos ocasionados pelo uso excessivo do fone de ouvido chegou-se à vários resultados. Para melhor compreensão dos resultados, foi organizado um quadro com a revisão integrativa dos artigos selecionados para a pesquisa.

Quadro 1: Artigos utilizados na pesquisa.

\begin{tabular}{|c|c|c|c|}
\hline Autor/Ano & $\begin{array}{c}\text { Base de } \\
\text { dados }\end{array}$ & Amostras & Resultados \\
\hline $\begin{array}{l}\text { Silva, et } \\
\text { al., (2012) }\end{array}$ & SCIELO & $\begin{array}{l}\text { Utilizou-se uma amostra de conveniência composta } \\
\text { por } 144 \text { estudantes, de ambos os gêneros, do Ensino } \\
\text { Médio de uma escola particular do Distrito Federal, } \\
\text { selecionados aleatoriamente. Foram excluídos } 10 \\
\text { indivíduos que apresentaram problemas de orelha } \\
\text { média; portanto, a coleta de dados se deu com os } 134 \\
\text { restantes, sendo } 56 \text { masculinos e } 78 \text { femininos, na } \\
\text { faixa etária entre } 14 \text { e } 19 \text { anos. }\end{array}$ & $\begin{array}{l}\text { Observou-se que apenas } 19,4 \% \text { (26) dos participantes passaram em } \\
\text { ambas as orelhas; } 29,9 \% \text { (40) passaram na orelha esquerda; } 29,1 \% \\
\text { (39) passaram na orelha direita; } 80,6 \% \text { (108) falharam em ambas as } \\
\text { orelhas; } 70,1 \% \text { (94) falharam na orelha esquerda; e } 70,9 \% \text { (95) } \\
\text { falharam na orelha direita. A porcentagem de homens que } \\
\text { apresentaram falha no exame foi significativamente superior à } \\
\text { porcentagem de mulheres que apresentaram essa alteração }(p=0,003) \text {. }\end{array}$ \\
\hline $\begin{array}{l}\text { Luz \& } \\
\text { Borja } \\
(2012)\end{array}$ & $\begin{array}{l}\text { Google } \\
\text { Acadêmico }\end{array}$ & $\begin{array}{l}\text { Estudo prospectivo observacional de corte transversal } \\
\text { realizado em três instituições de ensino da cidade de } \\
\text { Salvador- BA, sendo duas de rede pública e uma da } \\
\text { rede privada. Responderam ao questionário } 400 \\
\text { estudantes, de ambos os sexos, entre } 14 \text { e } 30 \text { anos que } \\
\text { referiram o hábito de utilizar estéreos pessoais. }\end{array}$ & $\begin{array}{l}\text { Os sintomas mais prevalentes foram hiperacusia }(43,5 \%) \text {, plenitude } \\
\text { auricular }(30,5 \%) \text { e zumbido }(27,5) \text {, sendo que o zumbido é o sintoma } \\
\text { mais presente na população mais jovem. Quanto aos hábitos diários: } \\
62,3 \% \text { usam frequentemente, } 57 \% \text { em intensidades elevadas, } 34 \% \text { em } \\
\text { períodos prolongados. Verificou-se uma relação inversa entre tempo } \\
\text { de exposição e a faixa de idade ( }(\mathrm{p}=0,000) \text { e direta com a prevalência } \\
\text { do zumbido. }\end{array}$ \\
\hline $\begin{array}{l}\text { Gonçalves } \\
\& \quad \text { Dias } \\
(2014)\end{array}$ & SCIELO & $\begin{array}{l}\text { Foram selecionados aleatoriamente } 30 \text { indivíduos de } \\
\text { ambos os gêneros, com idade entre } 16 \text { e } 29 \text { anos que } \\
\text { fazem uso constante de fones de ouvido e que } \\
\text { constituíram o grupo experimental. O grupo controle } \\
\text { foi composto por } 30 \text { indivíduos de ambos os gêneros, } \\
\text { com a mesma faixa etária do grupo experimental e } \\
\text { que não fazem uso constante de fones de ouvido. }\end{array}$ & $\begin{array}{l}\text { Verificou-se que a maioria dos participantes do grupo experimental } \\
\text { utiliza os fones de ouvido entre uma a duas horas diárias. Tal fato } \\
\text { corrobora com alguns estudos que revelam ser tal frequência suficiente } \\
\text { para surgimento posterior de comprometimentos a saúde auditiva dos } \\
\text { indivíduos. Ainda, } 76,67 \% \text { dos sujeitos pesquisados no grupo } \\
\text { experimental relatam apresentar queixas extra--auditivas provocadas } \\
\text { pelos tocadores portáteis de música. }\end{array}$ \\
\hline $\begin{array}{l}\text { Oliveira, et } \\
\text { al., (2017) }\end{array}$ & LILACS & $\begin{array}{l}\text { A amostra foi composta por } 20 \text { sujeitos de ambos os } \\
\text { gêneros, com faixa etária de } 16 \text { a } 27 \text { anos. As análises } \\
\text { dos resultados foram realizadas por orelha, } \\
\text { totalizando } 40 \text { orelhas. Os procedimentos adotados } \\
\text { foram aplicação de questionário, inspeção do conduto } \\
\text { auditivo externo, audiometria tonal e vocal, } \\
\text { imitanciometria e avaliação das intensidades de saída } \\
\text { dos fones supra-aurais e intra-aurais. }\end{array}$ & $\begin{array}{l}\text { Os fones supra-aurais possuíam saídas com intensidades equivalentes } \\
\text { e máximas significativamente maiores que os intra-aurais. Quando } \\
\text { comparadas as intensidades máximas ajustadas, constatou-se que os } \\
\text { usuários de fones intra-aurais utilizaram saídas com intensidades } \\
\text { equivalentes e máximas significativamente maiores que os usuários de } \\
\text { fones supra-aurais, observando-se uma correlação de média força entre } \\
\text { o tempo de uso e o uso diário, na frequência isolada de } 3000 \mathrm{~Hz} \text {. }\end{array}$ \\
\hline
\end{tabular}


De acordo com as previsões da Organização Mundial de Saúde (OMS), cerca de metade dos jovens entre 12 e 35 anos, isto é, 1,1 bilhão de pessoas em todo o mundo correm o risco de sofrer de perda auditiva. De acordo com a análise dos estudos, um dos principais motivos pode ser a exposição prolongada e excessiva aos sons altos, incluindo o barulho dos fones de ouvido.

Os ruídos altos, em geral, são extremamente prejudiciais aos ouvidos. Silva, et al., (2012) ressaltam que, ao usar fones de ouvido em volume alto, o risco é ainda maior, isso porque os fones ficam bem próximos ao ouvido e tal proximidade tem o efeito de aumentar o som equivalente a $9 \mathrm{~dB}$.

Nesse sentido, Luz e Borja (2012), ressaltam que quando as ondas sonoras chegam aos nossos ouvidos, elas fazem com que o tímpano vibre, com isso a vibração é transmitida ao ouvido interno até atingir a cóclea. A cóclea contém milhares de pequenos "pelos", que são as chamadas células ciliadas, e quando as vibrações sonoras atingem a cóclea, essas células se movem.

Desse modo, os fones de ouvidos, os quais são considerados como objetos modernos muito utilizado por jovens atualmente, como um meio de distração ou usado como um acessório, pode submeter as pessoas á barulhos bastante intensos, trazendo prejuízos a audição. Nos estudos de Gonçalves e Dias (2014), fica evidente que geração da tecnologia é propensa a usar mais aparelhos auditivos no futuro, se expor a uma intensidade acima de 80 decibéis diariamente pode provocar danos irreversíveis ao ouvido, no entanto, as consequências variam de acordo com o período de exposição sonora e a predisposição genética.

Em concordância com isso, Civitella (2020) expõe que sons altos provocam vibrações mais fortes, podendo causar perda da sensibilidade das células ciliadas, em alguns casos, as células podem se curvar muito por conta do barulho alto, causando a sensação de perda auditiva temporária e, depois de algum tempo, as células ciliadas se recuperam do ruído intenso e voltam a se mover. Entretanto, em outros casos, as células ciliadas nunca se recuperam, pois podem estar muito danificadas para continuar funcionando normalmente. Isso leva a perda auditiva permanente, e este tipo de problema auditivo induzido por ruído é quase impossível de se recuperar.

Ainda segundo Gonçalves e Dias (2014), são necessárias 8 horas de exposição a 80 dB para deteriorar a audição, apenas 1 hora a $89 \mathrm{~dB}$ e alguns minutos para $100 \mathrm{~dB}$. Não é difícil atingir essa intensidade de som com os fones de ouvido, pois de acordo com essas autoras, a maioria dos dispositivos de música atuais pode produzir sons de até $120 \mathrm{~dB}$, o que equivale a um nível de som em um show de rock.

Conforme os estudos de Oliveira, et al., (2017), os equipamentos tecnológicos de áudio e som estão cada vez mais potentes, e os sujeitos que escutam música com frequência nos modelos mais atuais de fones de ouvido, as ouvem com maior intensidade, podendo assim, ter sérios prejuízos à audição.

Além do mais, os usuários de fones de ouvido podem não ter consciência da gravidade do uso em excesso deste equipamento. De acordo com Luz e Borja (2012), os jovens dizem ter conhecimento dos danos que o uso excessivo dos fones de ouvidos pode causar, no entanto, continuam utilizando de maneira inadequada, por longos períodos e altas frequências. Esse comportamento se torna um risco ainda maior, a longo prazo, para a audição.

Ademais, Silva, et al., (2012) consideram que a alta prevalência de testes alterados indicam disfunção coclear, e ainda, suspeitam que o hábito de escutar músicas altas está provocando as alterações cocleares. Com isso, fica perceptível que a alta exposição de ruídos e o uso inadequado de fones de ouvido, causa sérios danos a saúde auditiva dos usuários deste aparelho.

\section{Considerações Finais}

O uso inadequado do fone de ouvido é um comportamento que reflete diversos danos para a audição dos usuários, pois sem o cuidado necessário pode causar dificuldades de audição nos indivíduos que utilizam excessivamente em volume 
elevado. Conforme a pesquisa, é possível evidenciar vários impactos do uso irregular de fones de ouvidos à audição, como risco de perda auditiva, disfunção e alteração coclear, zumbidos no ouvido, dentre outros. Pensando nisso, é importante que os usuários saibam quais são os malefícios do uso de fone de ouvido e como isso pode ser evitado, para que o sistema auditivo não sofra lesões e prejudique a sua qualidade de vida.

Outrossim, foi possível compreender que os modelos atuais de fones de ouvido são mais potentes, no que se refere a alta frequência, e podem ser ainda mais prejudiciais a audição, somado ao tempo diário excessivo utilizando tal aparelho. Além disso, os danos que podem ser mais intensos nos indivíduos com sensibilidade auditiva, contribuindo assim, para o desenvolvimento da perda auditiva leve ou de outros tipos de surdez, podendo levar à necessidade do uso de aparelho auditivo para minimizar o problema.

Dessa maneira, o profissional de fonoaudiologia é de suma importância para a orientação das pessoas que não sabem o modo correto de utilizar os fones de ouvidos, pois com a atuação de um profissional poderá ser informado os riscos e consequentemente evitar maiores números de problemas auditivos na população.

Sendo assim, a presente pesquisa poderá servir de base para estudos futuros relacionados com a importância de se compreender como os fones de ouvido podem afetar a audição, sendo direcionada não apenas para profissionais de Fonoaudiologia, mas também aos alunos, e pessoas que não conhecem os riscos de aparelhos tecnológicos para a saúde humana.

\section{Referências}

Araújo S. A. (2002). Perda auditiva induzida pelo em trabalhadores de metalúrgica. Revista Brasileira de Otorrinolaringologia. 68(1), 47-52, https://doi.org/10.1590/S0034-72992002000100008.

Barros S. M. S., et al. (2007). A eficiência das emissões otoacústicas transientes e audiometria tonal na detecção de mudanças temporárias nos limiares auditivos após exposição a níveis elevados de pressão sonora. Rev. Bras. Otorrinolaringologia,73, 592-598, https://doi.org/10.1590/S003472992007000500003 .

Borja A. L. V., et al. (2002). O que os jovens adolescentes sabem sobre as perdas induzidas pelo excesso de ruído? Revista de Ciências Médicas e Biológicas, 1(1), 86-98. https://doi.org/10.9771/cmbio.v1i1.4111.

Bouccara, D., Ferrary, E., \& Sterkers O. (2006). Effects of noise on inner ear. Med. Sciences, 22(11), 979-984, http://dx.doi.org/10.1051/medsci/20062211979. Brasil. (1981). Lei $n^{\circ}$ 6965/81, de 9 de dezembro de 1981. Regulamenta a profissão de fonoaudiólogo. Conselho Federal de Fonoaudiologia,

Brasil. (2006). Ministério da Saúde. Secretaria de Atenção à Saúde, Departamento de Ações Estratégicas. Perda Auditiva induzida por ruído (Pair). Ministério da Saúde.

Broca, V. S., \& Scharlach, R. C. (2014). O uso de questionário de autoavaliação na validação dos resultados do processo de seleção e adaptação de dispositivos eletrônicos de amplificação sonora individual. Rev. CEFAC. 16(6): 1808-1819. http://dx.doi.org/10.1590/1982-0216201410513.

Civitella, M., et al. (2020). Guia de Orientação: Avaliação e Intervenção no Processamento Auditivo Central.

Ercole, F. F., Melo, L. S., \& Alcoforado, C. L. G. C. (2014). Revisão Integrativa versus Revisão Sistemática. Rev Min Enferm. 18(1): 1-260. 10.5935/14152762.20140001.

Gonçalves, C. L., \& Dias F. A. M. (2014). Achados audiológicos em jovens usuários de fones de ouvido. Rev. CEFAC, 16(4), 1097-1108. https://doi.org/10.1590/1982-0216201422412.

Kopstein, D. (1999). Otorrinolaringologia e Fonoaudiologia no Processo de Indicação, Seleção e adaptação de protese auditiva. Monografia (Especialização em Audiologia Clínica). Centro de Especialização em Fonoaudiologia Clínica. 11.

Luz, T. S., \& Borja, A.V. (2012). Sintomas auditivos em usuários de estéreos pessoais. International archives of otorhinolaryngology, 16(2), 163-169, https://doi.org/10.7162/S1809-97772012000200003.

Mendes B. C. A, \& Barzaghi, L. (2011). Percepção e produção da fala e deficiência auditiva. In: Bevilacqua, M. C. et al. Tratado de Audiologia. Santos, 653669.

Miller, J. D. (1974). Effects of noise on people. J Acoust Soc Am. 1974, 56(3): 729-64. 10.1121/1.1903322.

Oliveira, M. F. F., et al. (2017). Fones de ouvido supra-aurais e intra-aurais: um estudo das saídas de intensidade e da audição de seus usuários. Audiol., Commun. Res. 22, e1783, https://doi.org/10.1590/2317-6431-2016-1783. 
Research, Society and Development, v. 10, n. 16, e345101623835, 2021

(CC BY 4.0) | ISSN 2525-3409 | DOI: http://dx.doi.org/10.33448/rsd-v10i16.23835

OMS. (2021). Organização Mundial de Saúde. Information session on the upcoming WHO Global standard for safe listening entertainment venues. OMS, 2021.

Portaria do INSS com respeito à perda auditiva por ruído ocupacional. Revista arquivos da fundação otorrinolaringologia, 1 (3): 86-102,

Santos, M. T. M., Russo, I. C. P. \& Borgiani, L. M. B. (2011). Interpretação dos Resultados da Avaliação Audiológica. In: M. Santos, T. M.; Russo, I. C. P., Prática da Audiologia Clínica. (8a ed.), Cortez, 12. 291-310.

Silman, S., \& Silverman, C. A. (1997). Basic audiologic testing. In: Silman, S.; Silverman, C.A. Auditory diagnosis: principles and applications. San Diego: Singular Publishing Group, 44-52.

Silva, V. G. (2017). Avaliação da possível associação de lesão de células ciliadas externas cocleares com a exposição à música amplificada em adolescentes. (Tese de doutorado apresentada ao Programa de Pós-Graduação em Ciências Médicas). Universidade de Brasília: Faculdade de Medicina, 2017.

Silva, V. G., et al. (2012). Prevalência de Alterações das Células Ciliadas Externas em Estudantes de uma Escola do Distrito Federal. Brazilian Journal of Otorhinolaryngology, Brasília: Universidade de Brasília, Faculdade de Medicina, 78(4), 91-97, https://doi.org/10.1590/S1808-86942012000400017.

Teles, R. M., \& Medeiros, M. P. H. (2007). Perfil audiométrico de trabalhadores do distrito industrial de Maracanaú - CE. Rev. soc. bras. Fonoaudiol, Ceará, 12(3), 233-239. https://doi.org/10.1590/S1516-80342007000300011.

Valeri, V. (2021). Quais são os tipos de fones existente- Básico sobre Fones. Oficina da Net. https://www.oficinadanet.com.br/hardware/25943-tudo-sobrefones-de-ouvido-sem-fio-bluetooth-basico-sobre-fones. 